
Specialists

\author{
Gulnara F. Biktagirova \\ Kazan (Volga region) Federal University, RUSSIA \\ Vyacheslav V. Utemov \\ Vyatka State University of Humanities, RUSSIA \\ Vera V. Khitryuk \\ Baranovichi State University, BELARUS
}

•Received 16 January 2016•Revised 04 April 2016•Accepted 04 April 2016

The relevance of the study is stipulated by the lack of applied technology of basic professional training program for middle level specialists for mastering Federal State Educational Standards, highlighting the integrated result of the development of the educational curricular (general and professional competences, knowledge, skills, experience). Thus, the aim of the research is to develop an effective training model for the new professional educational standards. The leading methods of the research are based on the formation and development of interconnected areas: professional individualization in the complex of special knowledge, skills and abilities; professional socialization in the formation of new mental structures and development of formed qualities in practice. The results of the experimental research implemented in Vyatka Culture College in 2011-2015 were the full course of training for 100 students with the major "Art and Culture". The proposed model connects learning outcomes with the formed-governmental graduate competencies, allowing to carry out professional activities.

Keywords: federal state educational standards of vocational professional education, competence, types of professional activity, competence-based approach

\title{
INTRODUCTION
}

\section{Relevance of research}

The educational system focused on mastering the knowledge accumulated by a mankind sets a natural limit for development of science, technologies, knowledge in

Correspondence: Vyacheslav V. Utemov,

Vyatka State University of Humanities, 26 Krasnoarmejskaya Street, Kirov 610002, RUSSIA

E-mail: utemov@dr.com

doi: 10.12973/ijese.2016.355a 
general (Biktagirova, 2011,Yarygin, 2013; Gilmullin \& Pupysheva, 2016; Kamalova \& Zakirova, 2015; Zaitseva, 2013). The purpose of modern professional education is to make future professional master a wide set of the interconnected and interacting qualities, such as initiative, mobility, dynamism and constructability, aspiration to self-education, possession of new technologies and ways of their application, ability to make independent decisions, adapt in the social and professional spheres, be able to work in team, be ready to overloads and stressful situations etc. (Kamalova \& Raykova, 2016; Sadovaya, Korshunova \& Nauruzbay, 2016). The list of similar qualities can be expanded considerably, but it is more important to reveal something general that brings them together. Such backbone part in modern education is assigned to the concept "competence".

\section{A competence-based approach in professional education}

We consider a competence-based approach as the objective phenomenon brought to life by social and economic, educational and pedagogical prerequisites. The modern economy imposes new requirements, which should be considered in programs of training specialists. These new requirements have interdisciplinary character and are universal for various spheres of activity. An attempt to meet these requirements forces to update the content of the studied disciplines and enter new pedagogical technologies, and new approaches to realization of the main professional educational program.

However, having almost 70 years' experience of training middle specialists for culture and art sphere, Vyatka college of culture use the concept professional competence", successfully combined with internal understanding of the pedagogical purpose of work. Professional competence is the completeness of qualities and abilities of the worker providing performance of actions by him according to the competence determined by requirements of a position.

\section{MATERIALS AND METHODS}

\section{Research methods}

The research used the following methods: analysis of normative documents, psychologic-pedagogical and methodological literature, products of educational activity, method of mental experiment, forecasting, systematization and generalization of facts and concepts, modeling, design, method of expert evaluations, analysis of results of educational activity, analysis and synthesis of experience of competence-based approach and competence-based model of realization of the main professional educational programs, diagnostic techniques, pedagogical experiment.

\section{Experimental base of research}

Skilled and experimental work was carried out by means of approbation of competence-based model of training during implementation of the existing educational standards of professional education consisting of formation and development of professional individualization in the complex of special knowledge, skills, developments and formations of personality in the course of formation of mental new growths and development of the created qualities in practical activities on the basis of Vyatka college of culture in 2011-2015, when more than 100 students passed a full course of training on major "Art and Culture". 


\section{Investigation phases}

The research was conducted in three stages:

- the first (preparatory) stage analyses the current state of the studied problem in the pedagogical theory and practice; develops the program of a technique of research;

- the second (basic) stage develops the root model of realization of the main professional educational program and implements it; carries out the system analysis of the current and intermediate results of research;

- the third (final) stage systematizes, judges and generalizes results of the research; specifies theoretical conclusions; carries out processing and registration of the received results of research.

\section{RESULTS}

\section{Synthesis of development of competence as assignments of a type of professional activity through realization of the offered model}

The operating Federal State Educational Standard of Secondary Professional Education (FSES SPE) 3+ generalizes competences of the trained experts for all directions of preparation through applied types of professional activity (Ministry of Education and Science of the Russian Federation, 2014). Therefore, in our opinion, the main educational objective at realization of this approach taking into account FSES SPE is a development of competence through assignment of a type of professional activity.

For realization of FSES SPE, we developed competence-based model of training (figure 1). Creation of conditions for motivation to training remains a paramount task. For this purpose, the curriculum from first year of training has to include special disciplines. Besides, according to educational standards, it is expedient to provide training of specialists on the basis of the relevant educational creative collectives, which consist of learners of the training directions. So, there are 6 educational creative collectives, where students gain both motivation to development of an educational program and experience of professional activity in college. If to speak about the volume of time allowed for work in collective, it is possible to tell that the student, being the member of collective, on average participates in 5 rehearsals a week, in 20 concerts and 30 displays a year, and also in enough competitions and festivals as a part of collective.

Level of motivation of students to future profession is annually reflected in testing of enthusiasm for future profession. So in 2015, enthusiasm is distributed as follows: 1 year of education $-60 \%$, 2 year of education $-40 \%$, 3 year of education $-65 \%$, 4 year of education $-80 \%$. Falling of interest at the beginning of the second year is connected with discrepancy of representation of the chosen profession with real characteristics, because of fragmentary understanding of a profession and ignorance of specifics and its contents. After the first year such understanding comes out. Such audit of interest will allow to strengthen work on adaptation to the received profession through system of the extracurricular activities reflected in competence-based model.

\section{Achievement of educational results according to standards}

Educational activity of college is considered by us as a process of interaction of mental, creative abilities, reflections and motivations. Intellectual and creative activity in the program of training of specialists of the sphere of culture and art are bound and occur in two directions: formation and development of professional 
individualization in a complex of special knowledge, skills, development and formation of the personality (professional socialization) in the course of formation of mental new growths and development of the created qualities in practical activities. The unity of individualization and socialization creates a harmonious combination of professional and personal in competence development.

The individualization passes through studying disciplines, practice, research works, and also through work in educational creative collectives.

Socialization is realized through the bases of professional modules. For this purpose, methodical council of college annually updates a matrix of the formed competences and a matrix of the measured competences for understanding of target reference points of development of professional modules.

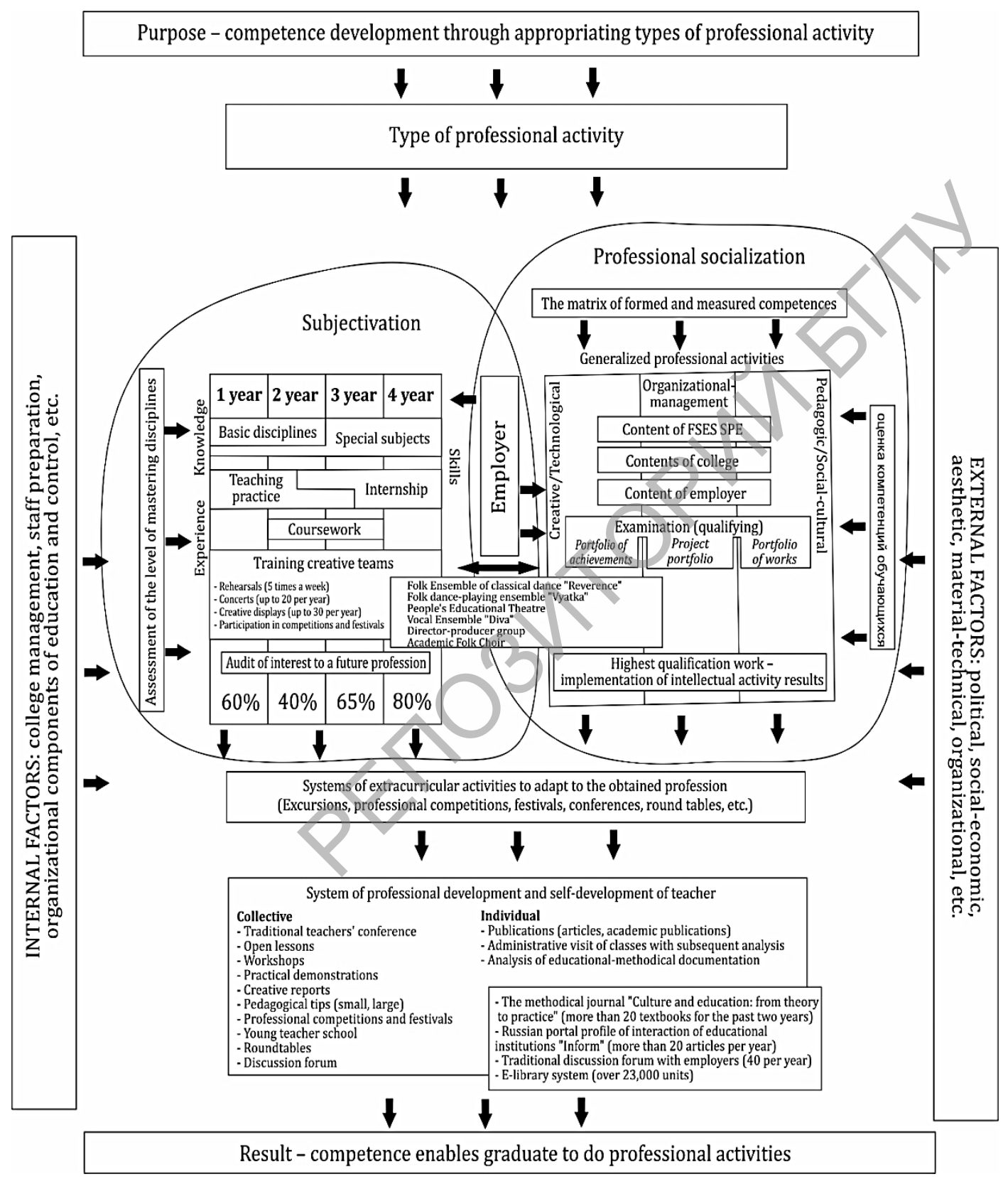

Figure 1. Competence-based model of training while implementing professional educational standards 
The generalized professional modules in the directions of preparation in college are creative/technological, organizational and administrative and pedagogical/welfare activities. Each module contains work practice. Maintenance of interdisciplinary courses is partially acquired through work and its judgment in educational creative collective and comes to the end with a qualification examination, which result is readiness for performance of a type of professional activity. At the moment, a form of such examination is the portfolio of achievements (diplomas, thanks, responses, characteristics of students), design portfolio (developed individual project within an interdisciplinary course of the module) and portfolio of works (development of lessons, developed repertoire plans, reports, papers, analyses of works, synthesis of experience). The analysis of the presented portfolio will allow to estimate formation of each competence, which is taken out for measurement.

The following component in model is the reflection.

The reflection is considered as the component of educational activity, which is a powerful tool of self-organization of cognitive activity. Object of reflection is directly professional knowledge, knowledge of own professional activity and activity in general. So, during extracurricular activities and practice after visiting of cultural and leisure establishments, viewings of the concert and dramatized programs on occupations students carry out the comprehensive analysis of action allowing to reflex the steady motives promoting understanding of the purposes of professional activity and to become motive for further development of educational program. Thus, training within professional modules considers the dependence described in methodical literature between a level of development of reflection and productivity of professional activity. In search of optimum complexity for each student of a concrete task, the main is to differentiate subjects of research works, performances, dramatized representations and etc.

Intellectual results due to creativity and reflection possess property of selfdevelopment and self-expansion of the saved-up experience. The reflection in this case do not play a recursion role in self-application of some saved-up result, and is shown as the appeal of the most formed professional activity of the student to own receptions and knowledge, as to object of the analysis-synthesis.

The result of development of an educational program is the final qualification work performed on a last year of education, which result is the developed and introduced product of intellectual activity (choreographic item, ceremonial action, dramatized representation, cinema image, soundtracks of pieces of music, etc.). Final work is a final point of the organization of educational research activity of students for all years of training in the offered model.

\section{Four-component competence-based model}

Thus, work on the "individualization" and "professional socialization" directions will allow to represent the formed result through interrelation of the general and professional competences making requirements to the college graduate. And the formed qualities and abilities of the person "are organized in some whole, reminding the structure of a pyramid" (Lomov, 1984) (figure 2).

In a four-component competence-based model the special sense has the edges of a pyramid and its top, illustrating pair and threefold interaction of competences. Therefore, educational program has the types of educational activity directed on registrations of edges of a pyramid: performance of term and educational research papers, and projects (Utemov, 2012). The following component of model - system of professional development and self-development of a teacher - is responsible for high-quality formation of a competence-based pyramid. 


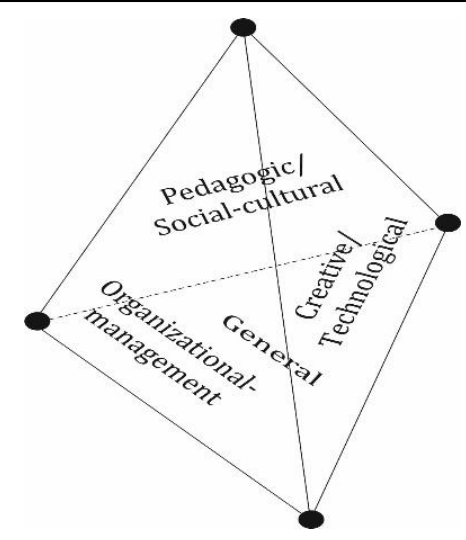

Figure 2. Four-component competence-based model

This system of actions is directed on comprehensive increase of competence and professional skill of each teacher, carried out for mastering teachers technologies and techniques of teaching and educational work, their creative application on occupations and in extracurricular activities, search of innovative, new and most rational and effective forms, and methods of the organization, carrying out and analysis of educational process. Formation of system of professional development and self-education of teachers in college is based under a uniform methodical subject with generalization and promotion of pedagogical experience. Synthesis of experience of teachers takes place in the different forms reflected in the model. Thanks to the existing system of methodical work in college uniform information and methodical support of realization of competence-based approach is formed.

Thus, considering internal and external factors in an educational program, the existing result of training allows to speak about the created competence of the graduate allowing to carry out types of professional activity.

\section{DISCUSSION}

Among the prospect of further development of the described model in system of professional education, we allocate work on realization of measurement of formation of competence in a form of a competence-based profile, that is development of such tasks, which show, what components of competence and of what degree are shown at the solution of this task. Thus each solution of a task will have competence-based structure (figure 3).

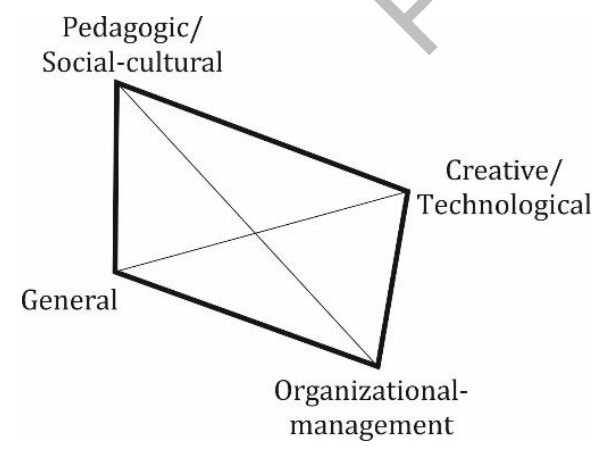

Figure 3. Competence-based profile of decisions

The competence-based structure of tasks is defined by weight coefficients of the formed competences. The received weight coefficients of the competences allow to construct a profile of the examinee (figure 4). 


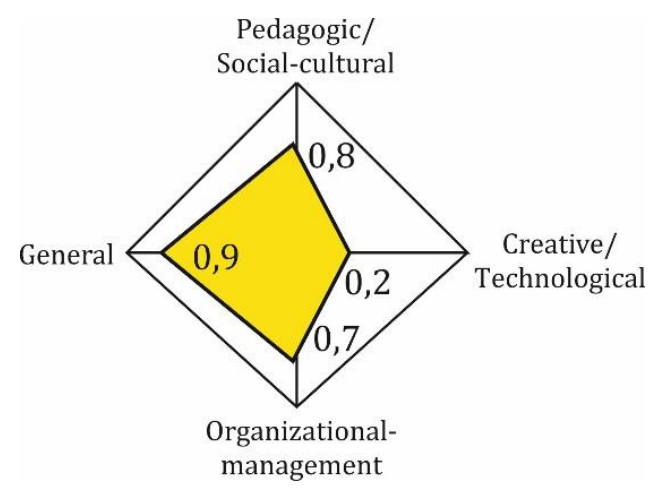

Figure 4. An example of a competence-based profile of a graduate

This profile can be for us very convenient, when updating the realized educational programs.

\section{CONCLUSION}

The offered competence-based model of formation of educational results while mastering Federal State Educational Standards of Secondary Professional Education for training mid-level specialists can become the basic element of the organization of educational and methodical work. It is worth noticing that for system of the general education educational standards had both subject educational results and personal and meta-subject results, i.e. the graduate of school will possess "new" set of educational achievements, and the following step of (professional) education has to be ready on training of such graduate with ensuring continuity of training. Metasubject results of training at the level of general education will become the main ones for formation on their basis of the general competences included in basic types of professional detail of future experts.

Therefore, the problem of adaptation of training materials and methods in the professional educational organizations with the general education has to become a key in methodical work in system of secondary professional education.

\section{RECOMMENDATIONS}

The materials of the article can be useful to pedagogical and administrative employees of the professional educational organizations realizing educational standards and seeking to increase the level of development of types of professional activity of graduates. Taking into account efficiency of approbation of the offered model, it is possible to allocate a number of the scientific problems and perspective directions demanding further consideration: deepening and extension of some provisions stated in the article, connected with accumulation of psychologicalpedagogic potential of model; development of scientific and methodical providing on adaptation by a basis of a professional educational program to programs of general education.

\section{ACKNOWLEDGMENTS}

The work is performed according to the Russian Government Program of Competitive Growth of Kazan Federal University. 


\section{REFERENCES}

Biktagirova G.F. (2011) Formation of social competence of students of pedagogical specialties and directions. Modern problems of science and education, 2011, № 4, c. 39

Gilmullin, M. F. \& Pupysheva, E. L. (2016). Workshop on Design and Implementation of Education Programs. Mathematics Education, 11(1), 35-44.

Kamalova, L. A. \& Raykova, E. (2016). The Quality and Criteria of Evaluation of Educational Work at the Universities of Russia at the Contemporary Stage. Mathematics Education, 11(1), 71-79.

Kamalova, L. A., Zakirova, V. G. (2015). The formation of the pedagogical values of future primary school teachers at the University. Review of European Studies, 7 (5), 1-9.

Lomov, B. F. (1984) Methodological and theoretical problems of psychology. Moscow, 226.

Ministry of Education and Science of the Russian Federation, 2014. The federal state educational standard of secondary professional education in 51.02.01 Amateur and folk arts (by types) approved by the order of the Ministry of Education and Science No. 1382 on October 27, 2014.

Ministry of Education and Science of the Russian Federation, 2014. The federal state educational standard of secondary professional education in 51.02.02 Welfare activity (by types) approved by the order of the Ministry of Education and Science No. 1356 on October 27, 2014.

Ministry of Education and Science of the Russian Federation, 2014. The federal state educational standard of secondary professional education in 51.02.03 Library science approved by the order of the Ministry of Education and Science No. 1357 on October 27, 2014.

Ministry of Education and Science of the Russian Federation, 2014. The federal state educational standard of secondary professional education in 53.02.08 Musical sound operator approved by the order of the Ministry of Education and Science No. 997 on August 13, 2014.

Ministry of Education and Science of the Russian Federation, 2014. The federal state educational standard of secondary professional education as 54.02.08 Techniques and art of photography approved by the order of the Ministry of Education and Science No. 1363 on October 27, 2014.

Sadovaya, V. V., Korshunova, O. V. \& Nauruzbay, Zh. Zh. (2016). Personalized Education Strategies. Mathematics Education, 11(1), 199-209.

Utemov, V. V. (2012) Documental software for independent work organization. Koncept, No. 9, ART 12113. URL: http://e-koncept.ru/2012/12113.htm.

Yarygin, O. N. (2013) System of formation of analytical activity competence for researcheducational personnel training: abstract of thesis on pedagigic sciences. Tolyatti, 44 .

Zaitseva, N. A. (2013). The role of education system in adaptation of graduates from Russian institutes and colleges at European enterprises (by example of service companies). Middle East Journal of Scientific Research, 13(5), 693-697.

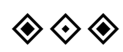

